\title{
Synthesis of 2-aminoethylarsonic acid
}

\section{A new synthesis of primary amines}

\author{
Kieran F. GEOGHEGAN* and Henry B. F. DIXON \\ Department of Biochemistry, University of Cambridge, Tennis Court Road, Cambridge CB2 1QW, U.K.
}

\begin{abstract}
2-Aminoethylarsonic acid was prepared from 2-chloroethylarsonic acid. The route constitutes a new procedure for making primary amines from haloalkanes; chloride was displaced by treatment with 2aminoethanol at $70^{\circ} \mathrm{C}$, and the product was converted into the required primary amine by treatment with periodate.
\end{abstract}

\section{INTRODUCTION}

The natural compound 2-aminoethylphosphonic acid $\left(\mathrm{NH}_{2} \mathrm{CH}_{2} \mathrm{CH}_{2} \mathrm{PO}_{3} \mathrm{H}_{2}\right)$ substitutes for 2-aminoethyl phosphate (ethanolamine phosphate, $O$-phosphoethanolamine, $\mathrm{NH}_{2} \mathrm{CH}_{2} \mathrm{CH}_{2} \mathrm{OPO}_{3} \mathrm{H}_{2}$ ) in the enzymic biosynthesis of CDP-ethanolamine from CTP by ethanolamine-phosphate cytidylyltransferase (Tamari et al., 1973), and this is the route by which it is incorporated into phospholipids. We wished to find whether 2-aminoethylarsonic acid, $\mathrm{NH}_{2} \mathrm{CH}_{2} \mathrm{CH}_{2} \mathrm{AsO}_{3} \mathrm{H}_{2}$, would also do so. Since anhydrides of arsonic acids are rapidly hydrolysed, this arsenical analogue should, if accepted as a substrate by the transferase, lead it to break down CTP continuously. The present paper reports the preparation of the arsonic acid for the study of the enzyme described in the following paper (Visedo-Gonzalez \& Dixon, 1989).

Since 2-chloroethylarsonic acid is available (see Adams et al., 1983), we considered the general difficulty in preparing primary amines by reaction of ammonia with a haloalkane. Many haloalkanes do not form a single phase with ammonia, so that reaction takes place at a phase boundary, and the primary amine formed enters the haloalkane phase, and is further alkylated despite any overall excess of ammonia. Water-soluble haloalkanes behave differently, and the reaction of 2-halo acids with ammonia to form 2-amino acids is satisfactory. If, however, the halogen is not activated, the reaction is very slow, e.g. the formation of taurine from 2-bromoethanesulphonic acid (Marvel et al., 1927; Marvel \& Bailey, 1943). It is not easily accelerated by heating, unless high pressures are used, because of the volatility of the ammonia.

Non-volatile derivatives of ammonia, such as phthalimide (Gabriel, 1887) and hexamethylenetetramine (Delépine, 1895; Bottini et al., 1973), have been used, but the latter had diminished reactivity. We chose a different

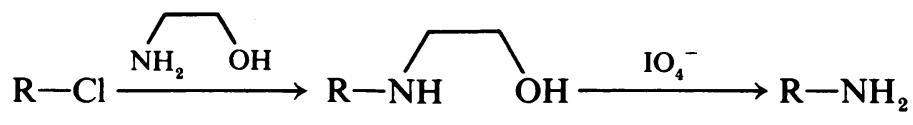

Scheme 1. Synthetic route nucleophile to displace halide, namely 2-aminoethanol, also, in effect, a derivative of ammonia. It can be used as both solvent and reagent. From the haloalkane RX it forms $\mathrm{RNHCH}_{2} \mathrm{CH}_{2} \mathrm{OH}$, and compounds of this structure are rapidly cleaved by periodate to yield $\mathrm{RNH}_{2}$, usually thousands of times faster than the corresponding diols (Barlow et al., 1966; Fields \& Dixon, 1968; Geoghegan et al., 1979). We have applied this procedure (Scheme 1) to the present synthesis. 1,2-Diaminoethane is less suitable than 2-aminoethanol as reagent, because compounds of the type $\mathrm{RNHCH}_{2} \mathrm{CH}_{2} \mathrm{NH}_{2}$ are oxidized much more slowly by periodate than is $\mathrm{RNHCH}_{2} \mathrm{CH}_{2} \mathrm{OH}$ (Fleury et al., 1949).

Gough \& King (1928) reported a failure to obtain 2aminoethylarsonic acid by treating 2-chloroethylarsonic acid with ammonia, and we found such a reaction very slow. A satisfactory synthesis was effected by the method outlined above, as follows.

The Appendix (Sparkes et al., 1989) gives two other applications of the synthetic method.

\section{EXPERIMENTAL}

2-Chloroethylarsonic acid $(1.04 \mathrm{mg}, 5.5 \mathrm{mmol})$, prepared by the classical procedure from 2-chloroethanol, via 2-hydroxyethylarsonic acid, following the details of Adams et al. (1983), was heated in 2-aminoethanol $(20 \mathrm{ml})$ at $80^{\circ} \mathrm{C}$ for $3 \mathrm{~h}$, after which high-voltage paper electrophoresis showed that all the 2-chloroethylarsonate had reacted. The mixture was dissolved in water $(100 \mathrm{ml})$ and passed through a column $(9 \mathrm{~cm} \times 2 \mathrm{~cm})$ of the strongly basic resin Zerolit FF (IP) SRA 71 in the acetate form. The column was washed with water $(5$ column volumes, i.e. $150 \mathrm{ml}$ ) to remove 2-aminoethanol. The product was eluted with $250 \mathrm{ml}$ of $1 \mathrm{M}$-acetic acid, and evaporated to dryness.

The material was then dissolved in water $(50 \mathrm{ml})$, adjusted with $2 \mathrm{M}-\mathrm{NaOH}$ to $\mathrm{pH} 8$, after which $\mathrm{NaIO}_{4}$ $(2.0 \mathrm{~g}, 9.4 \mathrm{mmol})$ dissolved in water $(30 \mathrm{ml})$ was added, and the $\mathrm{pH}$ was again adjusted to 7.5 after it had fallen on addition of the periodate solution. After $3 \mathrm{~h}$ at room temperature, high-voltage paper electrophoresis at $\mathrm{pH} 3.5$ showed complete conversion of the ninhydrinnegative initial reaction product (detected on paper by

* Present address : Pfizer Central Research, Eastern Point Road, Groton, CT 06340, U.S.A. 
its ability to chelate $\mathrm{Fe}^{3+}$ ions; Wade \& Morgan, 1953) into a ninhydrin-positive material of increased mobility towards the cathode. Glycerol $(2 \mathrm{ml})$ was then added to the solution to destroy the excess of periodate.

The solution was then poured on to a column $(60 \mathrm{ml})$ of the sulphonic resin Zerolit 225 SRC 15 in the acid form. The resin was washed with water until free of iodate (i.e. no precipitate with $\mathrm{AgNO}_{3}$ ), after which the product was displaced by washing with ammonia solution $(400 \mathrm{ml}, 1 \mathrm{M})$. The effluent was concentrated to an oil by evaporation. 2-Aminoethylarsonic acid crystallized from water on addition of ethanol; the yield was $0.3 \mathrm{~g}(32 \%)$.

Elemental analysis gave $\mathrm{C}, 13.8 ; \mathrm{H}, 4.80 ; \mathrm{N}, 8.19 \%$ (Calc. for $\mathrm{C}_{2} \mathrm{H}_{8} \mathrm{AsNO}_{3}$ : C, $14.2 ; \mathrm{H}, 4.77 ; \mathrm{N}, 8.28 \%$ ). ${ }^{1} \mathrm{H}$ n.m.r. at $400 \mathrm{MHz}$ : $\delta$ (p.p.m.) $\left({ }^{2} \mathrm{H}_{2} \mathrm{O}\right)$ setting $\left(\mathrm{Me}_{3} \mathrm{Si}\right)_{2} \mathrm{O}$ to $0.055: 2.53(2 \mathrm{H}, \mathrm{t}, 8 \mathrm{~Hz})$ and $3.43(2 \mathrm{H}, \mathrm{t}, 8 \mathrm{~Hz})$. There was slight splitting of the central line of each triplet, possibly because of restricted rotation about the $\mathrm{C}-\mathrm{C}$ bond, which could be due to attraction between the charged groups.

We thank many colleagues, especially Dr. D. M. Brown, Dr. R. M. Dixon, Dr. A. J. Kirby, Dr. E. D. Laue, Dr. T. A. Moore, Dr. G. A. Smith, Mr. M. J. Sparkes and Miss E. Visedo-Gonzalez, for discussion and help. K. F. G. was assisted financially by a Robert Gardiner Memorial Scholarship from the University of Cambridge and by a Studentship from King's College, Cambridge.

\section{REFERENCES}

Adams, S. R., Sparkes, M. J. \& Dixon, H. B. F. (1983) Biochem. J. 213, 211-215

Barlow, C. B., Guthrie, R. D. \& Prior, A. M. (1966) J. Chem. Soc. Chem. Commun. 268-269

Bottini, A. T., Dev, V. \& Klinck, J. (1973) Org. Synth. Collect. Vol. 5, 121-124

Delépine, M. (1895) C. R. Hebd. Séances Acad. Sci. 120, 501-502

Fields, R. E. \& Dixon, H. B. F. (1968) Biochem. J. 108, 883-887

Fleury, P., Courtois, J. \& Grandchamp, M. (1949) Bull. Soc. Chim. Fr. 88-94

Gabriel, S. (1887) Ber. Dtsch. Chem. Ges. 20, 2224-2236

Geoghegan, K. F., Ybarra, D. M. \& Feeney, R. E. (1979) Biochemistry 18, 5392-5399

Gough, G. A. C. \& King, H. (1928) J. Chem. Soc. 2426-2447

Marvel, C. S. \& Bailey, C. F. (1943) Org. Synth. Collect. Vol. 2, 563-565

Marvel, C. S., Bailey, C. F. \& Sparberg, M. S. (1927) J. Am. Chem. Soc. 49, 1833-1837

Sparkes, M. J., Dixon, H. B. F., Geohegan, K. F. \& VisedoGonzalez, E. (1989) Biochem. J. 260, 296-297

Tamari, M., Maget-Dana, R., Marmouyet, J. \& Douste-Blazy, L. (1973) Biochimie 55, 1311-1312

Visedo-Gonzalez, E. \& Dixon, H. B. F. (1989) Biochem. J. 260, 299-301

Wade, H. E. \& Morgan, D. M. (1953) Nature (London) 171, 529-530

\title{
APPENDIX
}

\section{Application of the synthetic method to other amines}

\author{
Michael J. SPARKES, Henry B. F. DIXON, Kieran F. GEOGHEGAN* and Emma VISEDO-GONZALEZ† \\ Department of Biochemistry, University of Cambridge, Tennis Court Road, Cambridge CB2 1QW, U.K.
}

Taurine and 2-aminoethylphosphonic acid were synthesized by the method of the main paper [Geoghegan \& Dixon (1989) Biochem. J. 260, 295-296], i.e. by treating the corresponding halo compound with 2 aminoethanol and then with periodate.

\section{INTRODUCTION}

Taurine has been made by treating 2-bromoethanesulphonic acid with ammonia, but the reaction is slow and takes several days (Marvel et al., 1927; Marvel \& Bailey, 1943). We found it convenient to use the procedure given in the main paper (Geoghegan \& Dixon, 1989 ), and so to replace the ammonia with 2-aminoethanol and cleave the product with periodate.

2-Aminoethylphosphonic acid is also biologically important, and occurs both in phosphonolipids [reviewed by Florin-Christensen et al. (1986) and by Kittredge \& Roberts (1969)] and in proteins (Stevenson et al., 1974). It has been synthesized both (Finkelstein, 1946) by the Hofmann degradation of (EtO) ${ }_{2} \mathrm{P}(\mathrm{O}) \mathrm{CH}_{2} \mathrm{CH}_{2} \mathrm{CONH}_{2}$, which requires several steps to prepare, and (Chavanne, 1947; Kosolapoff, 1947) by the phthalimide method, by an Arbuzov reaction on $N$-(2-bromoethyl)phthalimide. Similarly Carayon-Gentil et al. (1967) used an Arbuzov reaction on 2-bromoethylamine, after protecting the amino group by substitution with $(\operatorname{PrO})_{2} \mathrm{P}(\mathrm{O})$-. The present method seems simpler. Since the phosphono group of 2-bromoethylphosphonic acid became masked, probably esterified, when this compound was treated with 2-aminoethanol, we used its diethyl ester (from which the free acid is normally made), and de-esterified it in the course of the synthesis.

Hence both compounds were conveniently made by the procedure used for aminoethylarsonic acid. Since

* Present address : Pfizer Central Research, Eastern Point Road, Groton, CT 06340, U.S.A.

$\dagger$ Present address: 12 Paseo San Gervasio, 08022 Barcelona, Spain. 